Proceedings of the International Symposium on Physics of Materials (ISPMA 14), September 10-15, 2017, Prague

\title{
Microstructure and Mechanical Properties of Ti-15Mo Alloy Prepared by ECAP
}

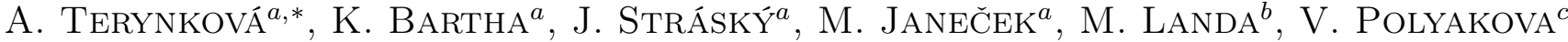 \\ AND I. SEMENOVA ${ }^{c}$ \\ ${ }^{a}$ Department of Physics of Materials, Charles University, Ke Karlovu 5, 121 16, Prague, Czech Republic \\ ${ }^{b}$ Institute of Thermomechanics, Academy of Sciences, Dolejškova 5, 182 00, Prague, Czech Republic \\ ${ }^{c}$ Institute of Physics of Advanced Materials, UFA State Aviation Technical University, \\ K. Marx Street 12, 450 000, Ufa, Russia
}

\begin{abstract}
Metastable beta titanium alloys are perspective materials for use in biomedicine due to their excellent mechanical and physical properties, which can be improved by severe plastic deformation by reducing grain size and inserting a high degree of deformation. Ti-15Mo alloy was subjected to 1-4 passes of equal channel angular pressing in a die with channels intersecting at an angle of $120^{\circ}$ at the temperature of $250^{\circ} \mathrm{C}$. The microstructure observed by means of electron backscatter diffraction showed deformed and highly twinned structure, but the deformation was not sufficient for achieving an ultrafine grained material. The microhardness increased with the increasing number of equal channel angular pressing passes. The Young modulus was measured by the methods of resonant ultrasound spectroscopy and also increased with the number of equal channel angular pressing passes. Significant increment of elastic modulus can be attributed to the formation $\omega$-phase particles.
\end{abstract}

DOI: 10.12693/APhysPolA.134.787

PACS/topics: 61.66.Dk, 61.72.Mm, 62.20.de, 62.20.Qp

\section{Introduction}

Metastable $\beta$ Ti-alloys are commonly used in aircraft industry and belong to perspective materials for use in biomedicine due to their good biocompatibility, high strength, excellent fatigue and corrosion resistance and low density in comparison with steels [1]. Nowadays, an $\alpha+\beta$ alloy, Ti- $6 \mathrm{Al}-4 \mathrm{~V}$, is the most used titanium alloy for orthopaedic implants manufacturing [2]. However, vanadium is a toxic element and its use in a biomedical material is often considered adverse [3]. Therefore, Ti$15 \mathrm{Mo}$ alloy is an appropriate candidate for replacing the $\mathrm{Ti}-6 \mathrm{Al}-4 \mathrm{~V}$ alloy. The next important attribute of $\beta \mathrm{Ti}-$ alloys is a low modulus of elasticity, which is also important for use in biomedicine. Refinement of microstructure is a possible way to enhance strength without increase of the modulus of elasticity.

Investigated Ti-15Mo alloy undergoes several phase transformations during thermomechanical processing. The solution treated (ST) material consists of $\beta$ phase matrix with body-centered cubic structure and metastable $\omega$-phase with hexagonal symmetry [4]. The $\omega$-phase formed already during quenching is referred to as $\omega_{\text {ath }}\left(\omega\right.$ athermal) [5]. The particles of this $\omega_{\text {ath }}$ phase are small (in nanoscale range) and coherent with the parent $\beta$ matrix [6]. During aging at temperatures in the range of $150{ }^{\circ} \mathrm{C}$ to $350{ }^{\circ} \mathrm{C}$ the $\omega$-particles become stabilized by diffusion process - this phase is being referred to as $\omega_{\text {iso }}$ ( $\omega$ isothermal) $[4,7]$.

*corresponding author; e-mail: annaterynkova@gmail.com
Severe plastic deformation by equal channel angular pressing (ECAP) was applied as a method of grain refinement [8]. The severe plastic deformation (SPD) enhances the strength of the material via increased dislocation density and grain refinement [9]. This study investigates the microstructure, microhardness and elastic modulus of $\mathrm{Ti}-15 \mathrm{Mo}$ alloy after ECAP processing.

\section{Material and experimental}

The metastable $\beta$-alloy, Ti-15Mo used in this study was delivered by Carpenter Co. and contains 15 wt.\% of molybdenum and negligible amount of other elements (0.185 wt.\% O, 0.090 wt.\% Si, 0.030 wt.\% Fe, 0.014 wt.\% $\mathrm{N}, 0.007$ wt.\% C, and 0.001 wt.\% H) (as certified by supplier). The alloy was solution treated at temperature of $810^{\circ} \mathrm{C}$ for $4 \mathrm{~h}$ and quenched in water.

Deformation by ECAP was performed at Ufa State Aviation Technical University at temperature of $250^{\circ} \mathrm{C}$ in a die with channels intersecting at angle of $\Phi=120^{\circ}$. Therefore the equivalent inserted deformation per pass according to Von Mises is $\varepsilon_{\mathrm{VM}}=0.67$ [10].

The microstructure of specimens was observed by ZEISS Auriga Compact FIB-SEM microscope using electron backscatter diffraction (EBSD). The microhardness was measured by the Vickers method using Qness Q10a instrument and elastic constants were evaluated by resonant ultra-sound spectroscopy (RUS) method [11, 12].

\section{Results and discussion}

Figure 1 shows EBSD image of samples cut perpendicularly to the direction of processing. The left part 

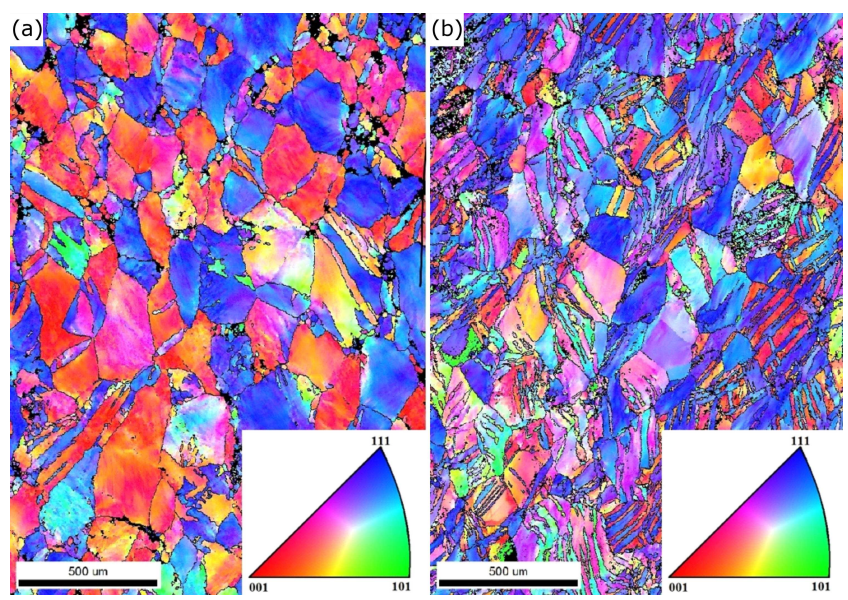

Fig. 1. (a) Inverse pole map figure of cross-section of samples after 2 passes. (b) Inverse pole map figure of cross-section of samples after 4 passes.

shows microstructure after two ECAP passes. Despite the grains are clearly deformed and some small grains are observable, the microstructure is not significantly refined and the grain size is in the range of hundreds of micrometers. Image on the right hand side shows highly twinned structure after 4 ECAP passes. It can be therefore concluded that $4 \mathrm{ECAP}$ passes (corresponding to Von Mises equivalent strain of $\left.\varepsilon_{\mathrm{VM}}=2.67\right)$ are sufficient for the formation of ultrafine grained structure. This is in accordance with the observations of $\mathrm{Ti}-15 \mathrm{Mo}$ alloy deformed by high pressure torsion [13].

Detailed EBSD image in Fig. 2 represents an example of a twinned grain in the sample after 4 ECAP passes together with the simulation of the crystal orientation of the matrix and the twins. It is obvious that the plane of twinning is $\{112\}$. It is known that the system of twinning in BCC structure is $\{112\}\langle 111\rangle[14]$. Misorientation between matrix and twins was determined from EBSD measurement as $52^{\circ}$, which corresponds to the abovementioned system.

Both the microhardness and the modulus of elasticity grow with increase of number of ECAP passes as it is graphically depicted in Fig. 3. Values of elastic modulus and microhardness of solution treated material ("0 passes") originate from [15] and [13], respectively. Microstructure refinement may cause an increase of microhardness due to increased concentration of lattice defects, while the elastic modulus should either remain unchanged or exhibit decrease due to the presence of open volume defects. Significant increase of the elastic modulus can be rather ascribed to changes of phase composition after ECAP processing. Recall that material was processed at $250^{\circ} \mathrm{C}$, which is sufficient for increasing volume fraction of the $\omega$-phase [16]. Moreover, formation of the $\omega$-phase might be enhanced in dynamic conditions (during deformation) [17]. The increased volume fraction of the $\omega$-phase has an immense effect on the macroscopic modulus of elasticity [7]. It is therefore suggested that the increase of the elastic modulus was caused by growth of the $\omega$-phase particles.

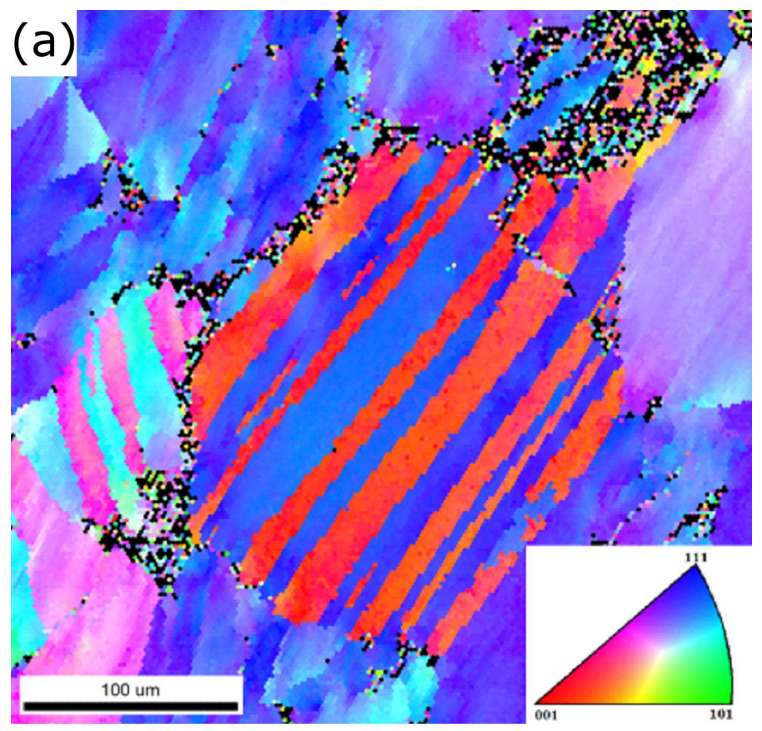

(b)

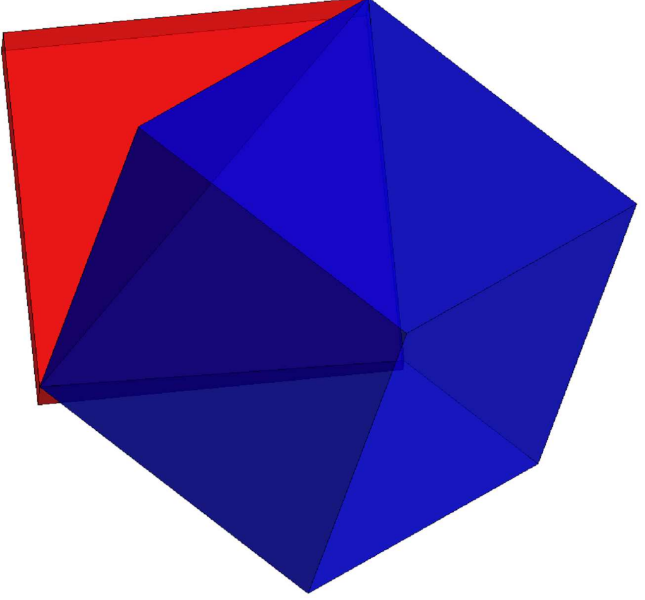

Fig. 2. (a) Example of twinning as observed by EBSD - 4 ECAP passes. (b) Simulation of orientation of matrix (red) and twin (blue).

The increase of the values of elastic modulus $(1,2,3$, and 4 passes) correlates with the increase of microhardness. $\omega$-phase is hard and brittle [1] and formation of the $\omega$-phase particles is known to increase the strength and hardness of the titanium alloys [18]. Therefore, the increase of the volume fraction of the $\omega$-phase is the common reason for the simultaneous increase of both elastic modulus and microhardness.

\section{Conclusions}

The evolution of microhardness, elastic constants and the microstructure of $\mathrm{Ti}-15 \mathrm{Mo}$ alloy prepared by ECAP was studied. Following conclusions can be drawn from this investigation:

- ECAP processing of Ti-15Mo alloy leads to deformed and heavily twinned microstructure. The concentration of twins grows with the number of ECAP passes. 


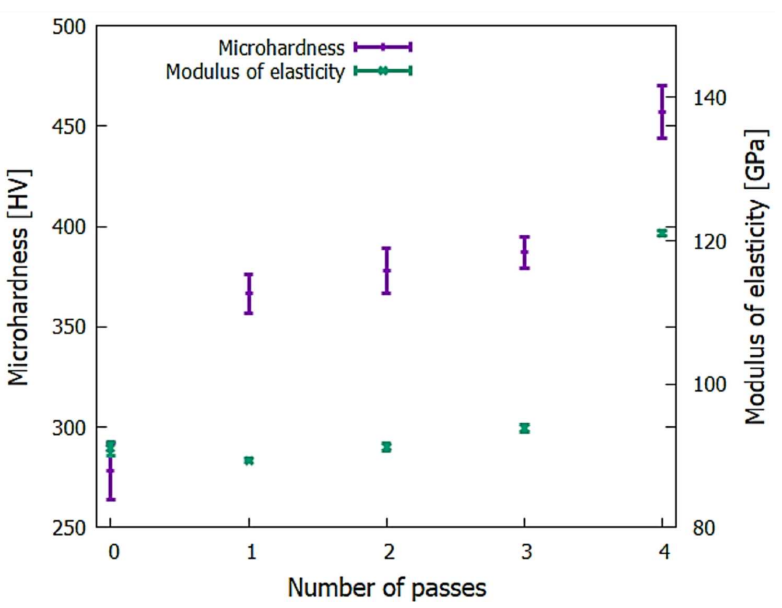

Fig. 3. Evolution of microhardness (purple, left axis) and modulus of elasticity (green, right axis) with the number of ECAP passes.

- The system of twinning of $\mathrm{Ti}-15 \mathrm{Mo}$ alloy is $\{112\}[111]$.

- The microhardness and the modulus of elasticity increase simultaneously with the number of ECAP passes which can be caused by the increase of volume fraction of the $\omega$-phase formed during ECAP processing.

\section{Acknowledgments}

This work was supported by the project "Nanomaterials centre for advanced applications", Project No.CZ.02.1.01/0.0/0.0/15 003/0000485, financed by ERDF. This study was also supported by Czech Science Foundation under the grant 17-20700Y. K.B. acknowledges the financial support by the Grant Agency of Charles University (GAUK), project No. 1106216.

\section{References}

[1] G. Lütjering, J.C. Williams, Titanium, Springer, Berlin 2003
[2] H.J. Rack, J.I. Qazi, Mater. Sci. Eng. C 26, 1269 (2006).

[3] J. Stráský, Ph.D. Thesis, Charles University in Prague, 2014

[4] P. Zháňal, P. Harcuba, J. Šmilauerová, J. Stráský, M. Janeček, B. Smola, M. Hájek, Acta Phys. Pol. A 128, 779 (2015).

[5] S.K. Sikka, Y.K. Vohra, R. Chidambaram, Prog. Mater. Sci. 27, 245 (1982).

[6] H.P. Ng, A. Devaraj, S. Nag, C.J. Bettles, M. Gibson, H.L. Fraser, B.C. Muddle, R. Banerjee, Acta Mater. 59, 2981 (2011).

[7] J. Nejezchlebová, M. Janovská, H. Seiner, P. Sedlák, M. Landa, J. Šmilauerová, J. Stráský, P. Harcuba, M. Janeček, Acta Mater. 110, 185 (2016).

[8] R.Z. Valiev, T.G. Langdon, Prog. Mater. Sci. 51, 881 (2006).

[9] M. Janeček, J. Čížek, J. Stráský, K. Václavová, P. Hruška, V. Polyakova, S. Gatina, I. Semenova, Mater. Character. 98, 233 (2014).

[10] Y. Iwahashi, J. Wang, Z. Horita, M. Nemoto, T.G. Langdon, Scr. Mater. 35, 143 (1996).

[11] A. Migliori, J.L. Sarrao, W. Visscher, T.M. Bell, M. Lei, Z. Fisk, R.G. Leisure, Phys. B 183, 1 (1993).

[12] P. Sedlák, H. Seiner, J. Zídek, M. Janovská, M. Landa, Exp. Mech. 54, 1073 (2014).

[13] K. Václavová, J. Stráský, V. Polyakova, J. Stráská, J. Nejzchlebová, H. Seiner, I. Semenova, M. Janeček, Mater. Sci. Eng. A 682, 220 (2017).

[14] Q.H. Tang, T.C. Wang, Acta Mater. 46, 5313 (1998).

[15] K. Václavová, M.Sc. Thesis, Charles University in Prague, 2015.

[16] J. Šmilauerová, P. Harcuba, D. Kriegner, M. Janeček, V. Holý, Acta Mater. 100, 126 (2015).

[17] S. Banerjee, U.M. Naik, Acta Mater. 44, 3667 (1996).

[18] J.C. Williams, Titanium and Titanium Alloys: Scientific and Technological Aspects, Plenum Press, New York 1976. 